\title{
Epigenetic reprogramming of melanoma cells by vitamin C treatment
}

\author{
Christopher B Gustafson ${ }^{1}$, Cuixia Yang ${ }^{2,5}$, Kevin M Dickson ${ }^{1}$, Hongwei Shao², Derek Van Booven ${ }^{1}$, J William Harbour ${ }^{3,4}$, \\ Zhao-Jun Liu ${ }^{2,3^{*}}$ and Gaofeng Wang ${ }^{1,3,4^{*}}$
}

\begin{abstract}
Background: The loss of 5-hydroxymethylcytosine $(5 \mathrm{hmC})$ has been identified as a novel epigenetic hallmark for melanoma. One of the known mechanisms underlying the loss of $5 \mathrm{hmC}$ is the decrease in expression of ten-eleven translocation family dioxygenase (TET) genes, which encode enzymes that catalyze the generation of 5hmC. Overexpressing TET2 was shown to partially reestablish a normal $5 \mathrm{hmC}$ profile in melanoma and decrease invasiveness in rodents. However, the feasibility to overexpress TETs in patients remains unclear. We and others have recently demonstrated that TETs require vitamin $C$ as a cofactor to generate $5 \mathrm{hmC}$. This finding prompted us to test whether vitamin $\mathrm{C}$, as an alternative to overexpressing TETs, could rebuild $5 \mathrm{hmC}$ content in melanoma.
\end{abstract}

Results: Consistent with previous reports, we found that the expression of TETs was decreased in various melanoma cell lines. In contrast, the expressions of sodium-dependent vitamin C transporters (SVCTs) were down-regulated in cell lines derived from melanoma metastases. Treatment of vitamin $C$ at the physiological level $(0.1 \mathrm{mM})$ promoted the content of $5 \mathrm{hmC}$ in melanoma cell lines derived from different stages toward the level of healthy melanocytes, which was comparable to the effect of overexpressing TET2. Vitamin C treatment decreased the malignancy of metastatic A2058 cells by inhibiting migration and anchorage-independent growth, while not exerting any effect on the rate of proliferation. Further, vitamin C treatment caused alterations in genome-wide transcriptions shown by RNA-seq, predominantly in ArhGAP30 and genes involved in extracellular matrix remodeling, which could underlie the decreased malignant phenotypes.

Conclusions: Our data support the idea that vitamin C treatment increases $5 \mathrm{hmC}$ content in melanoma cells, while causing a decrease in tumor-cell invasiveness and clonogenic growth in soft agar. Thus, vitamin C could be a potential epigenetic treatment for melanoma.

Keywords: Vitamin C, 5-hydroxymethycytosine, Epigenetic reprogramming, RNA-seq, Melanoma

\section{Background}

Aberrant epigenetic alterations, along with genetic mutations, are known to contribute to the onset of cancer. Recently, the loss of 5-hydroxymethylcytosine (5hmC) has been identified as a novel hallmark for most, if not all, types of cancer (including melanoma) [1-4]. The content of $5 \mathrm{hmC}$ is relatively high in healthy melanocytes but is gradually lost during the progression from benign

\footnotetext{
* Correspondence: zliu@med.miami.edu; gwang@med.miami.edu

${ }^{2}$ Department of Surgery, University of Miami Miller School of Medicine, Miami, FL 33136, USA

'John P. Hussman Institute for Human Genomics, Dr. John T. Macdonald Foundation Department of Human Genetics, University of Miami Miller School of Medicine, Miami, FL 33136, USA

Full list of author information is available at the end of the article
}

nevi through advancing stages of primary and metastatic melanoma [3]. $5 \mathrm{hmC}$ is converted from 5-methylcytosine $(5 \mathrm{mC})$, the major epigenetic modification of mammalian DNA, by a group of enzymes termed TET (ten-eleven translocation) family dioxygenases $[5,6]$. TETs can further oxidize $5 \mathrm{hmC}$ to 5-formylcytosine and 5-carboxylcytosine, which are eventually replaced by unmodified cytosine thus completing the process of demethylation. The cascade oxidation of $5 \mathrm{mC}$ by TETs and the ensuing base excision repair has been recognized as the most consistent mechanism underlying the active demethylation of DNA [7].

The loss of $5 \mathrm{hmC}$ demonstrates an epigenetic drift in the dynamics of DNA methylation-demethylation, which could potentially be involved in the pathogenesis of melanoma. Interestingly, $5 \mathrm{hmC}$ is relatively stable and is 
distributed with unique patterns in the genome $[8,9]$. Further, $5 \mathrm{hmC}$ recruits different sets of binding proteins, as compared to $5 \mathrm{mC}$, and correlates with unique transcription profiles [10-12]. In addition to being a DNA demethylation intermediate, $5 \mathrm{hmC}$ serves as an epigenetic mark with unique regulatory capabilities. Therefore, the global loss of $5 \mathrm{hmC}$ can change genome stability and genomewide transcription patterns, which ultimately leads to a cascade of phenotypic transformations from healthy melanocytes toward malignant melanoma.

One of the known mechanisms underlying the loss of $5 \mathrm{hmC}$ in melanoma is a lower expression of the TET and isocitrate dehydrogenases (IDH) genes [3,4], which encode enzymes that catalyze the production of 2oxoglutarate, a co-substrate for the TET enzymes. It has been shown that overexpressing TET2 could partially reestablish a normal $5 \mathrm{hmC}$ profile in cultured melanoma cells and decrease their invasiveness in modeled animals [3]. These findings suggest that rebuilding the $5 \mathrm{hmC}$ content can be a potential treatment for melanoma. However, the feasibility to clinically overexpress TETs or IDHs in patients suffering from melanoma remains unclear.

TETs belong to the iron and 2-oxoglutarate-dependent dioxygenase superfamily. These dioxygenases utilize $\mathrm{Fe}^{2+}$ as a cofactor, 2-oxoglutarate as a co-substrate, and some of them require vitamin $\mathrm{C}$ (ascorbate) as an additional cofactor to achieve full catalytic activity. We and other groups have recently shown that vitamin $C$ induces the generation of $5 \mathrm{hmC}$, most likely by acting as a cofactor for TET dioxygenases to hydroxylate $5 \mathrm{mC}$. Vitamin $\mathrm{C}$ at physiological levels has been shown to increase the global content of $5 \mathrm{hmC}$ in vivo and in vitro [13-17]. This previously unknown function of vitamin $\mathrm{C}$ in modulating DNA demethylation prompted us to test whether vitamin $C$, as an alternative to overexpressing TETs or IDHs, could be a potential epigenetic treatment for melanoma by rebuilding $5 \mathrm{hmC}$ profiles.

\section{Results}

The expression of TETs was decreased in melanoma cell lines

We first evaluated the expression level of TETs (TET1, TET2, and TET3) in primary cultured healthy human melanocyte lines (FOM-113) and various melanoma cell lines using qRT-PCR. These melanoma cell lines include those that are derived from the radial growth phase (RGP, SBcl2 and WM35), vertical growth phase (VGP, WM278 and WM3248) and metastatic stage (C8161, A2058). Consistent with a previous report [3], we found that the expression of TET1 and TET2 was consistently decreased in all melanoma cell lines examined, as compared to the normal melanocyte line (Figure 1A). TET3 was not detectable by qRT-PCR in our lab. Of the cell lines evaluated, the lowest expression level of both TET1 and TET2 was observed in two metastatic melanoma cell lines.

\section{The expression of SVCT2 was decreased in metastatic melanoma cell lines}

The uptake and accumulation of vitamin $\mathrm{C}$ by cells are mainly via sodium-dependent vitamin $\mathrm{C}$ transporters (SVCT). There are two types of SVCTs, which are, SVCT1 and SVCT2. We then measured the expression of SVCT1 and SVCT2 in the same melanoma cell-line panel used for the evaluation of TETs. Both SVCT1 and SVCT2 were detectable in these cell lines by qRT-PCR, although the expression level of SVCT1 is much lower than that of SVCT2 (approximately 3 cycles in difference). The mRNA levels of SVCT1 and SVCT2 were either decreased or increased in the examined melanoma cell lines compared to the normal melanocytes. However, only in those metastatic melanoma cell lines (C8161 and A2058), the expression of both SVCT1 and SVCT2 was consistently decreased, as compared to the healthy melanocytes (Figure 1B). Interestingly, it has been shown that the uptake rate of ascorbate (the dominant form of vitamin $\mathrm{C}$ in the plasma) by melanoma cells (SK-MEL-131) is only approximately $50 \%$ of the uptake rate by healthy melanocytes [18]. A decreased expression of SVCTs presumably could also result in a lower efficiency in vitamin $\mathrm{C}$ uptake in these metastatic melanoma cell lines. These results suggest that a local vitamin $\mathrm{C}$ deficiency, along with a decreased level of TETs, may contribute to the global loss of $5 \mathrm{hmC}$ in metastatic melanoma cells.

\section{Vitamin C treatment promoted $5 \mathrm{hmC}$ content in melanoma cells toward that of healthy melanocytes}

Next, we tested whether vitamin $C$ treatment could increase the global content of $5 \mathrm{hmC}$ in melanoma cells. The content of $5 \mathrm{hmC}$ was relatively high in healthy melanocytes (FOM-113) but was barely detectable by dotblot assay in SBcl-2 (RGP), WM278 (VGP), and A2058 (metastasis) melanoma cells cultured in a vitamin $\mathrm{C}$-free medium. These cell lines were chosen based on their decreased expression of both SVCT1 and SVCT2. The average concentration of vitamin $\mathrm{C}$ in the plasma of humans is at approximately $0.05 \mathrm{mM}$ range and could reach concentrations of up to approximately $0.15 \mathrm{mM}$ [19]. We reasoned that a relatively higher concentration of vitamin $C$, but still in the range of physiological concentration, could compensate for the down-regulated SVCTs in melanoma cells. In this case, vitamin $\mathrm{C}$ at $0.1 \mathrm{mM}$ was chosen for treatment. There was no obvious change in the content of $5 \mathrm{hmC}$ in healthy melanocytes after treatment with vitamin $\mathrm{C}(0.1 \mathrm{mM})$ for $48 \mathrm{~h}$, which could be explained by the possible saturation of dot-blot signals. In contrast, vitamin $\mathrm{C}$ treatment dramatically increased the 

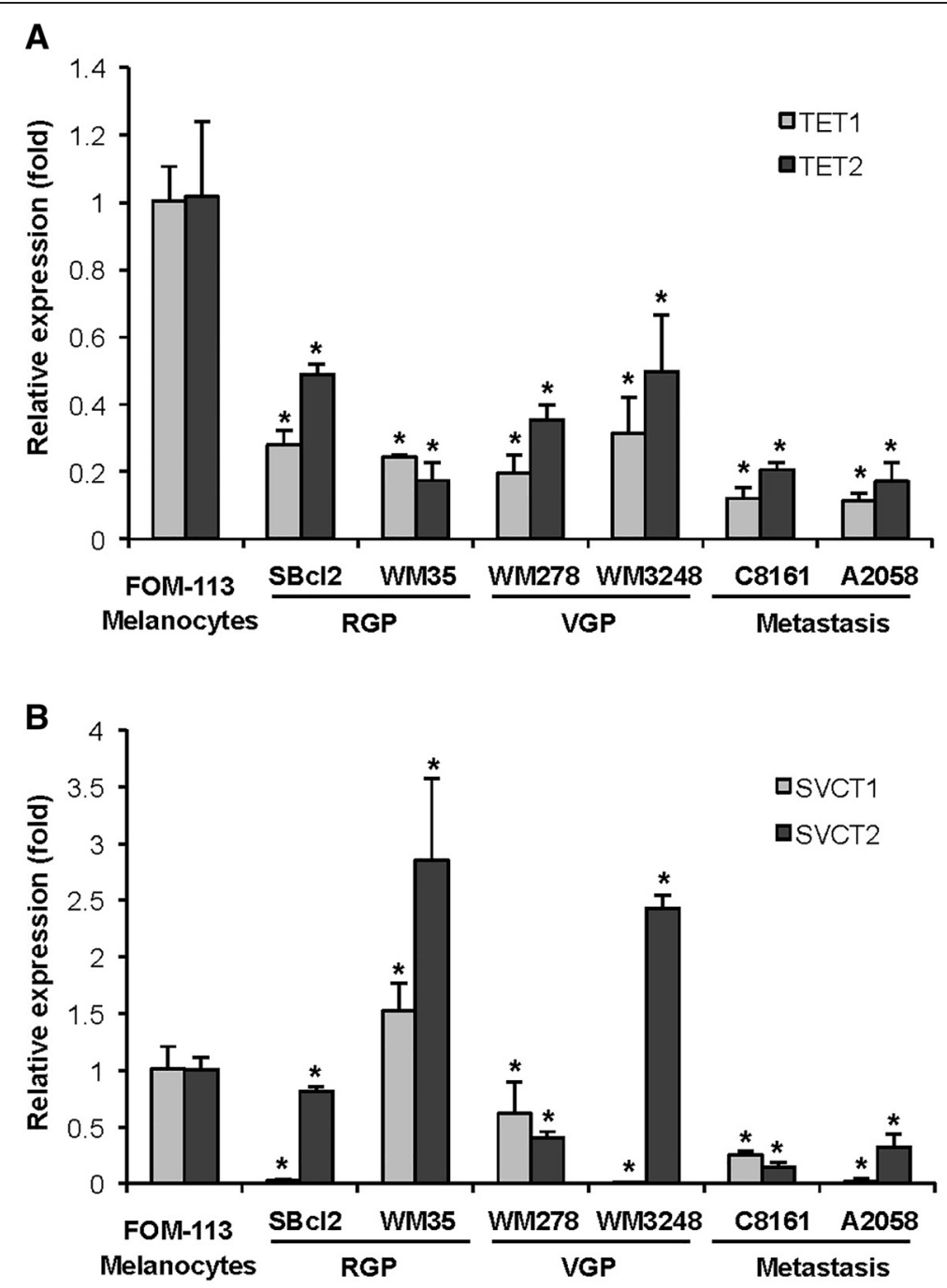

Figure 1 The relative transcription levels of TETs and SVCTs in melanoma cells. Levels of TETs and SVCTs (mean) in a healthy melanocyte line are set up as ' 1 '. (A) The mRNA levels of TET1 and TET2, measured by qRT-PCR, are decreased in melanoma cell lines derived from RGP, VGP, and metastatic stages compared to a healthy melanocyte line FOM-113. (B) The mRNA levels of SVCTs are either decreased or increased in the examined melanoma cell lines. Comparatively, the transcription levels of both SVCTs are decreased in the melanoma cell lines $(\mathrm{C8161,A2058)}$ derived from the metastatic stage. (Mean $\pm S D, * P<0.05)$.

content of $5 \mathrm{hmC}$ in all three melanoma cell lines toward the level in healthy melanocytes (Figure 2). After treatment with vitamin $\mathrm{C}$, the content of $5 \mathrm{hmC}$ in WM278 cells and A2058 cells was increased to approximately $80 \%$ of control melanocytes, while the content of $5 \mathrm{hmC}$ in SBcl-2 cells was only increased to approximately $50 \%$ of control melanocytes. It remains unknown to us why the response of SBcl-2 cells was less than the other cell lines, though the expression of TETs and SVCTs in SBcl-2 cells of RGP was at similar levels as the other melanoma cell lines. Nevertheless, these results suggest that vitamin $C$ at physiological levels indeed promotes the content of $5 \mathrm{hmC}$ toward the level of healthy melanocytes, which is comparable to the effect of overexpressing TET2, as shown previously [3].

\section{Vitamin C time-dependently increased $5 \mathrm{hmC}$ content in} A2058 cells

Previous studies have implicated a potential pharmacological effect of elevating vitamin $C$ to higher concentrations in the plasma $(>0.3 \mathrm{mM})$ on certain types of cancer [20]. Pharmacological levels of vitamin C in the plasma can only be achieved through intravenous injections. Although intravenous injections in a certain way may complicate the delivery of vitamin $C$ to patients, we still tested whether vitamin $\mathrm{C}$ at pharmacological levels has an even stronger effect on $5 \mathrm{hmC}$ generation in melanoma cells. The A2058 cell line was used as a cell model in the first published study on $5 \mathrm{hmC}$ reestablishment in melanoma. Following this, we chose the A2058 cell line as a model also considering their decreased 


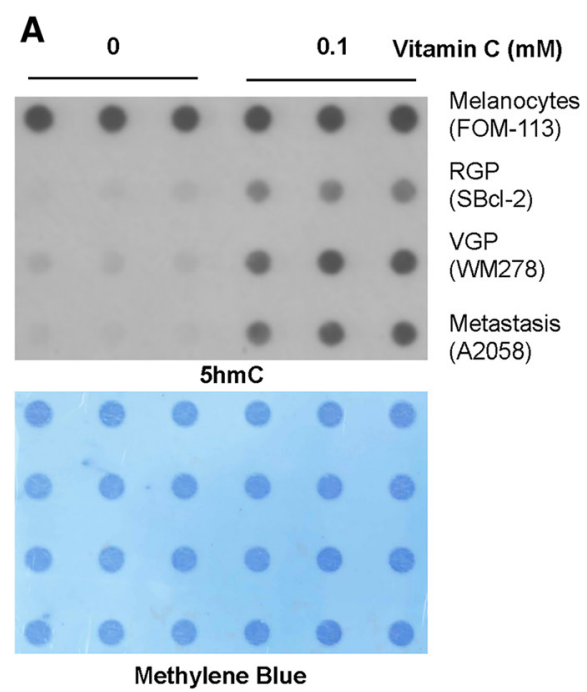

B

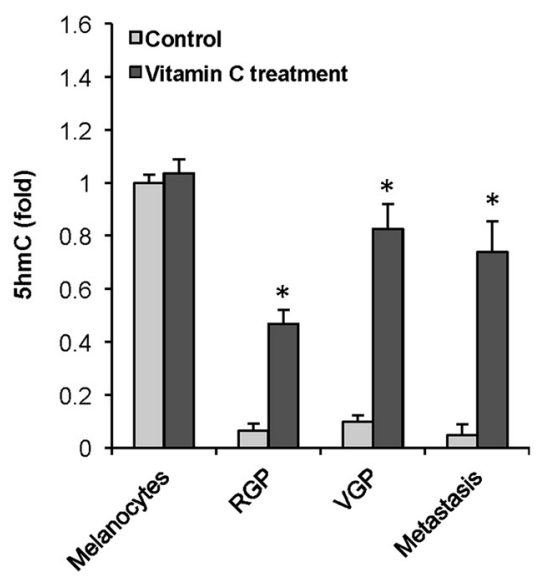

Figure 2 Vitamin C treatment raises $5 \mathrm{hmC}$ content toward that in healthy melanocytes. (A) The dot blot shows vitamin C treatment (0.1 mM) for $48 \mathrm{~h}$ and increases the global content of $5 \mathrm{hmC}$ in melanoma cells at different stages (RGP, VGP, and metastatic) toward the level in healthy melanocytes. (B) The semi-quantitative analysis of the dot-blot indicates that vitamin C significantly promotes $5 \mathrm{hmC}$ generation in melanoma cells. (Mean \pm SD, ${ }^{*} P<0.01$ ). The level of $5 \mathrm{hmC}$ (mean) in untreated melanocytes is set up as ' 1 '. The relative levels of $5 \mathrm{hmC}$ in melanoma cells with or without vitamin $C$ treatment are shown.

expression of TETs and SVCTs. As described above, the $5 \mathrm{hmC}$ signal was barely detectable in A2058 cells when cultured without vitamin C. After supplementation of vitamin $\mathrm{C}(0.01 \mathrm{mM})$ in the medium for $24 \mathrm{~h}$, we found that the content of $5 \mathrm{hmC}$ increased about sixfold, and $0.1 \mathrm{mM}$ vitamin $\mathrm{C}$ induced further increase in $5 \mathrm{hmC}$ (nearly ninefold), as compared to the basal level (Figure 3A \& B). However, $5 \mathrm{hmC}$ was induced to a similar level $(P>0.05)$ in response to vitamin $C$ treatment, regardless of how low $(0.1 \mathrm{mM})$ or high $(0.5 \mathrm{mM}$ and $1 \mathrm{mM})$ the concentrations were. This suggests that vitamin $C$ at pharmacological levels does not incur greater benefits in promoting $5 \mathrm{hmC}$

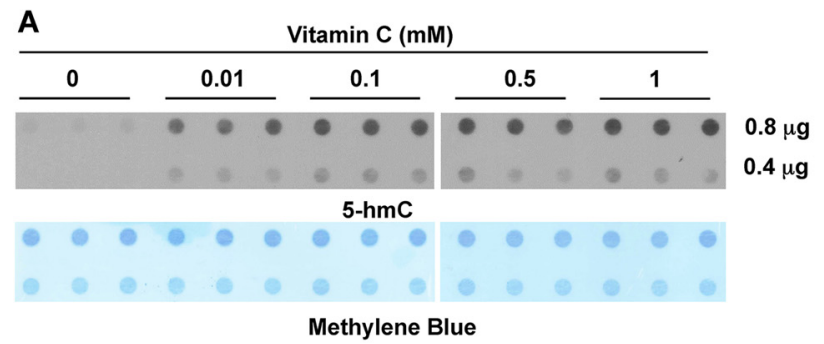

C

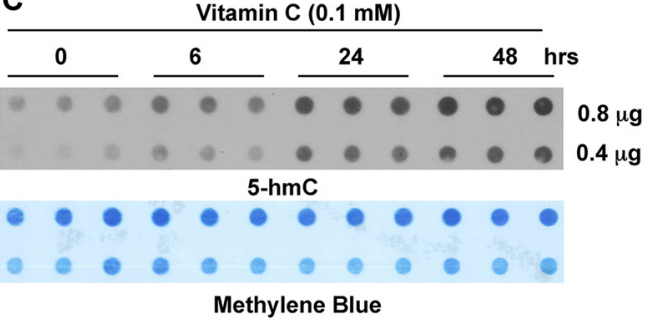

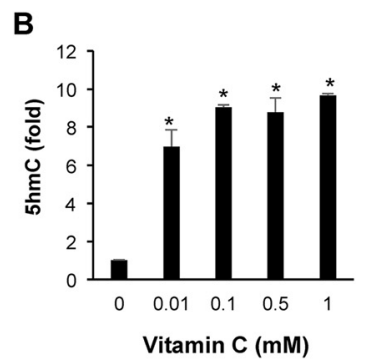

D

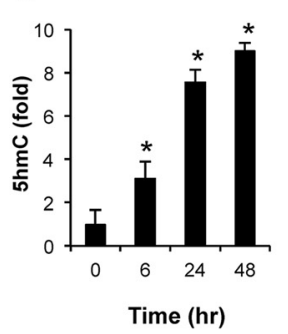

Figure 3 Vitamin C treatment increases the content of 5hmC in A2058 melanoma cells. (A to B) The dot-blot and semi-quantitative analysis of the dot-blot show that treatment with vitamin $\mathrm{C}(0.01 \mathrm{mM})$ increase $5 \mathrm{hmC}$ to approximately sixfold of the basal level. Higher concentrations of vitamin $\mathrm{C}(0.1 \mathrm{mM}$ to $1 \mathrm{mM}$ ) induce $5 \mathrm{hmC}$ generation at a similar level (approximately ninefold in increase). (C to $\mathbf{D})$ Vitamin $\mathbf{C}$ treatment (0.1 mM) time-dependently increases the content of $5 \mathrm{hmC}$ in A2058 cells as showed by the dot-blot and the semi-quantitative analysis of the dot-blot. Quantitative data are relative amounts of $5 \mathrm{hmC}$. 
generation in melanoma cells, as compared to vitamin $\mathrm{C}$ at physiological levels.

Similar to what we previously observed in non-malignant cells [13], vitamin $C$ treatment also enhanced the generation of $5 \mathrm{hmC}$ in A2058 cells in a time-dependent manner. The $5 \mathrm{hmC}$ content was increased approximately threefold in $6 \mathrm{~h}$, approximately eightfold in $24 \mathrm{~h}$, and approximately ninefold in a 48 -h post vitamin $C$ treatment $(0.1 \mathrm{mM})$ (Figure $3 \mathrm{C} \& \mathrm{D}$ ). This result suggests that TET enzymes, though at a lower level than in healthy melanocytes, are ready to generate $5 \mathrm{hmC}$ in melanoma cells but are waiting for vitamin $\mathrm{C}$ to assist the hydroxylation reaction. Thus, the accumulated vitamin $C$ within the cells led to a timedependent increase of $5 \mathrm{hmC}$. It is important to note that the difference between the time points of $24 \mathrm{~h}$ and $48 \mathrm{~h}$ was miniscule, which could in part be due to the fact that $5 \mathrm{hmC}$ is not maintained during DNA replication in these rapidly growing cells. These results once again indicate that vitamin $\mathrm{C}$ at physiological levels partially reestablishes the content of $5 \mathrm{hmC}$ in melanoma cells, which is comparable to the effect of overexpressing TET2 in the same cell line [3].

\section{Vitamin C treatment inhibited the malignant phenotype of melanoma cells}

We then questioned what the functional consequences of the vitamin C-increased $5 \mathrm{hmC}$ content could be in terms of melanoma malignancy. According to our observation described above, vitamin $\mathrm{C}$ at physiological concentrations is able to restore the global content of $5 \mathrm{hmC}$ as efficiently as to that of pharmacological concentrations in melanoma cells in vitro. In that regard, we tested the effect of vitamin $\mathrm{C}$ at physiological concentrations on behaviors of melanoma cells. In the cell proliferation analysis, we observed that treatment with vitamin $\mathrm{C}$ at physiological concentrations $(0.05 \mathrm{mM}$ to $0.1 \mathrm{mM})$ did not evidently affect the growth rate of A2058 cells (Figure 4A) as well as healthy melanocytes (data not shown). In contrast, vitamin $\mathrm{C}$ at pharmacological concentrations $(0.5 \mathrm{mM}$ to $2 \mathrm{mM})$ significantly inhibited not only A2058 cell proliferation $(P<0.05)$, but also the cell growth rate of healthy melanocytes (data not shown). Since such high concentrations $(0.5 \mathrm{mM}$ to $2 \mathrm{mM}$ ) of vitamin $\mathrm{C}$ treatment appeared to be toxic to many types of non-malignant cells including healthy melanocytes, pharmacological concentration of vitamin $\mathrm{C}$ treatment might not be a practicable option for cancer therapy. This might explain why vitamin $C$ treatment at pharmacological concentrations resulted in inconsistent therapeutic results for cancer [20]. Overall, our results suggest that vitamin $\mathrm{C}$ at physiological concentrations does not affect cell proliferation of both melanoma (A2058) cells and healthy melanocytes. It appears to be safe for clinical application.

Interestingly, although vitamin $\mathrm{C}$ at physiological concentrations had little effect on cell proliferation of melanoma (A2058) cells, it indeed altered melanoma cell migration and in vitro transformation. In our experiments using the transwell cell migration assay to evaluate the effect of vitamin $\mathrm{C}$ treatment at physiological concentrations on melanoma cell migration, we treated A2058 cells with or without vitamin $\mathrm{C}(0.1 \mathrm{mM})$ for $24 \mathrm{~h}$ and tested their ability to migrate in the transwell. We observed that vitamin $\mathrm{C}$ at a physiological level (0.1 mM) significantly inhibited A2058 cell transwell migration (Figure 4B).
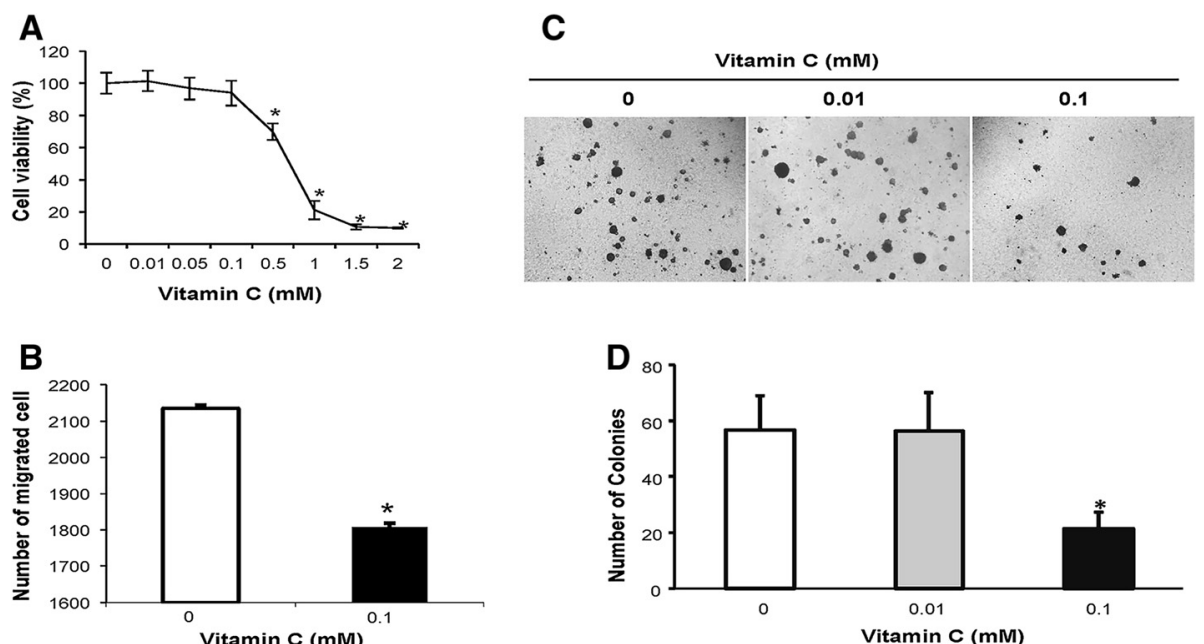

Figure 4 Vitamin C treatment decreases the malignant phenotype of A2058 cells in vitro. (A) MTT assay shows that Vitamin C at pharmacological levels ( $0.5 \mathrm{mM}$ to $2 \mathrm{mM}$ ) inhibits A2058 cell proliferation while it does not affect A2058 cell proliferation at physiological levels $(0.05 \mathrm{mM}$ to $0.1 \mathrm{mM})$. (B) Treatment with vitamin C (0.1 mM) mitigates A2058 cell migration as tested by the transwell assay. (C to D) Vitamin C treatment (0.1 mM) inhibits the anchorage-independent growth of A2058 cells, and $0.01 \mathrm{mM}$ vitamin C has no obvious effect. A representative image of soft-agar assay is shown in (C). Quantitative data of colonies formed (\#/well) in the soft-agar assay (D). ( $\left.{ }^{*} P<0.05\right)$. 
Anchorage-independent growth is one of the hallmarks of transformation. It is considered the most accurate and stringent in vitro assay to detect malignant transformation of cells in vitro. We further examined the effect of vitamin $\mathrm{C}$ treatment at physiological concentrations on anchorage-independent growth of melanoma cells. We observed that supplementation of vitamin $\mathrm{C}$ $(0.1 \mathrm{mM})$ drastically inhibited A2058 cell colony formation in the soft agar, while $0.01 \mathrm{mM}$ vitamin $\mathrm{C}$ did not obviously affect the colony formation (Figures $4 \mathrm{C} \& \mathrm{D}$ ). This result suggests that vitamin $C$ at a physiological level $(0.1 \mathrm{mM})$ mitigated malignant transformation of melanoma cells. Considered together, our results demonstrate that vitamin $C$ at physiological concentrations could significantly reduce the malignant phenotype of A2058 cells in vitro by inhibiting cell migration and transformation but not suppressing cell proliferation. Hence, vitamin $\mathrm{C}$ at physiological concentrations might be applied as a safe and clinically sound therapeutic option.

\section{Vitamin C treatment shifted the transcriptome of melanoma cells}

We examined the possible mechanisms that could reveal how vitamin $C$ suppresses cell migration and anchorageindependent growth of A2058 cells. Vitamin C is a micronutrient and has been proven to serve many different functions, including anti-oxidation and acting as a cofactor for a list of iron and 2-oxoglutarate-dependent dioxygenases. We and others have shown that the effect of vitamin $\mathrm{C}$ on $5 \mathrm{hmC}$ generation is independent of its property as a general reducer [13-17]. Of the known enzymes requiring vitamin $\mathrm{C}$ as a cofactor, only TETs and its mediated hydroxylation of $5 \mathrm{mC}$ to $5 \mathrm{hmC}$ have known direct impacts on gene transcriptions. Thus, we hypothesized that the vitamin C-induced global increase of $5 \mathrm{hmC}$ could, at least in part, be responsible for the phenotypic consequences of A2058 cells by changing gene expression profiles.

To test our hypothesis, we conducted RNA-seq to evaluate the influence of vitamin $C$ treatment on the transcriptome of A2058 cells. In order to minimize potential secondary effects in the long term, A2058 cells were treated with vitamin $\mathrm{C}$ at physiological concentrations $(0.1 \mathrm{mM})$ for $48 \mathrm{~h}$. DNA and RNA were simultaneously extracted from A2058 cells cultured in the same wells ( $n=3$ per group). After the vitamin C-induced $5 \mathrm{hmC}$ were confirmed by dot-blot assay (data not shown), RNA were submitted to the Sequencing Core of John P. Hussman Institute of Human Genomics at the University of Miami. We applied rigorous bioinformatic and statistical approaches to analyze the RNA-seq data. The results showed that 1,147 genes were differentially expressed by EdgeR, 789 genes by DEseq, and 74 genes by Bayseq, respectively. However, only 66 genes including a few of noncoding transcripts were significantly and differentially expressed in the analyses of all three methods - EdgeR, DESeq, and BaySeq (Figure 5). Of the 66 genes, seven genes were down-regulated while the rest of the 59 genes were up-regulated. Then, we chose the top ten genes for validation based on fold changes ( $\geq 1.6$-fold increase or $\leq 0.7$ fold decrease) in multiple callers. The expression changes of all ten genes had been verified by qRT-PCR (Table 1). However, the ten verified genes may not be able to fully explain the effects of vitamin $C$ on the altered malignant phenotype of A2058 cells. The most significant change induced by vitamin $\mathrm{C}$ treatment occurs in the gene rho GTPase activating protein 30 (ARHGAP30, ztenfold increase). Unfortunately, western blot using different sources of antibody did

\section{$\operatorname{EdgeR}(n=1147)$}

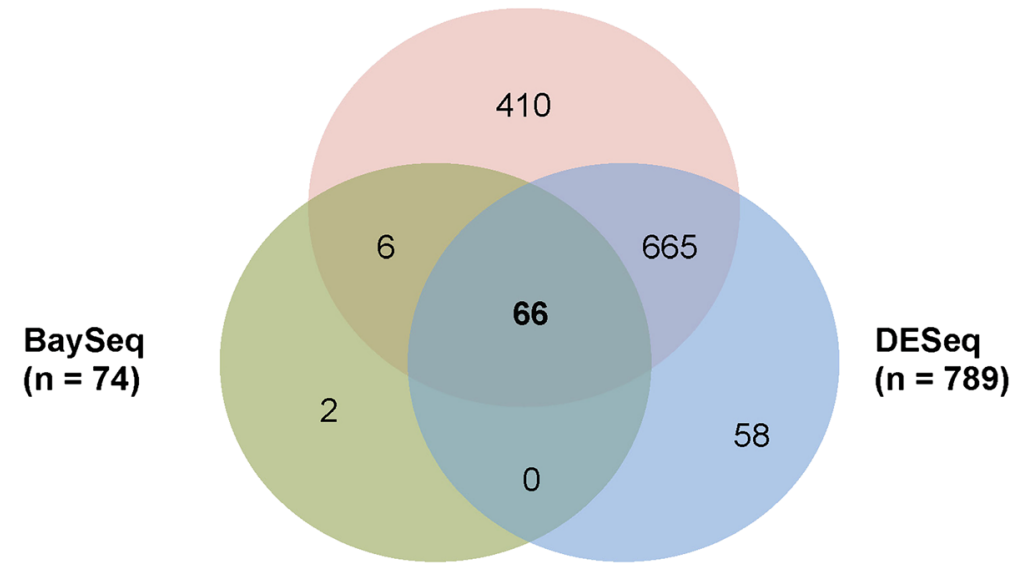

Figure 5 Vitamin C treatment shifts the transcriptome of A2058 cells. After vitamin C ( $0.1 \mathrm{mM})$ treatment for $48 \mathrm{~h}$, differentially expressed genes are identified by EdgeR (1,147 genes), DEseq (789 genes), and Bayseq (74 genes) analysis. However, only 66 genes are overlapped by the analyses of all three methods. 
Table 1 Differentially expressed genes in A2058 cells used by vitamin C treatment

\begin{tabular}{|c|c|c|c|c|c|c|}
\hline \multirow[t]{2}{*}{ No } & \multirow[t]{2}{*}{ Symbol } & \multirow[t]{2}{*}{ Gene } & \multicolumn{2}{|c|}{ RNA-seq (DESeq) } & \multicolumn{2}{|c|}{ qRT-PCR } \\
\hline & & & Fold & $P$ value & Fold & $P$ value \\
\hline 1 & ARGHAP30 & Rho GTPase activating protein 30 & 15.2 & $4.73 \times 10^{-21}$ & 10.3 & $2.2 \times 10^{-5}$ \\
\hline 2 & TRIM63 & Tripartite motif containing 63, E3 ubiquitin-protein ligase & 5.3 & $2.15 \times 10^{-05}$ & 4.3 & $2.2 \times 10^{-5}$ \\
\hline 3 & PTPN7 & Protein tyrosine phostaphatase, non-receptor type 7 & 3.8 & 0.01 & 2.6 & $8 \times 10$ \\
\hline 4 & SOCS3 & Suppressor of cytokine signaling 3 & 1.9 & $1 \times 10^{-4}$ & 2 & $9 \times 10^{-3}$ \\
\hline 5 & FAP & Fibroblast activation protein, alpha & 1.7 & $3.43 \times 10^{-21}$ & 1.6 & 0.01 \\
\hline 6 & GPRIN3 & GPRIN family member 3 & 1.7 & $5 \times 10^{-5}$ & 2 & $3 \times 10^{-4}$ \\
\hline 7 & TIMP3 & TIMP metallopeptidase inhibitor 3 & 1.6 & $5 \times 10^{-5}$ & 1.5 & 0.01 \\
\hline 8 & MAGEA4 & Melanoma antigen family A & 1.6 & $5 \times 10^{-5}$ & 1.8 & $1 \times 10^{-4}$ \\
\hline 9 & SERPINE2 & Serpin, peptidase inhibitaor clade $E$, member 2 & 0.67 & $2.5 \times 10^{-4}$ & 0.79 & 0.01 \\
\hline 10 & SLITRK2 & SLIT and NTRK-like family member 2) & 0.49 & $1 \times 10^{-4}$ & 0.66 & $2 \times 10^{-3}$ \\
\hline
\end{tabular}

not present a specific ARHGAP30 band at the expected size. Nevertheless, we have decided to examine ARHGAP30 at protein level in future studies. By pathway enrichment analysis, we found that the most prominent changes occurred in the extracellular matrix (ECM)-remodeling pathway including TIMP metallopeptidase inhibitor 3 (TIMP3) and GPRIN family member 3 (GPRIN3). Changes in these genes may explain, at least in part, the inhibitory effect of vitamin C on A2058 cell migration and anchorageindependent growth.

\section{Discussion}

Recent discoveries of the epigenetic abnormalities in cancer provide unprecedented opportunities to reprogram malignant cancer cells and alter them toward healthy cells by targeting related enzymes that are responsible for the epigenetic modifications [21]. The conversion of $5 \mathrm{mC}$ to $5 \mathrm{hmC}$ requires a catalytic complex that is at least composed of the TET enzymes, the cosubstrate 2-oxoglutarate, and the cofactor $\mathrm{Fe}^{2+}$. We, for the first time, reported that vitamin $\mathrm{C}$ is an additional cofactor for TETs to generate $5 \mathrm{hmC}$. This was subsequently verified by three other groups and is now widely accepted [13-17]. Interestingly, the loss of $5 \mathrm{hmC}$ has been identified as a novel hallmark for most, if not all, types of cancer [1-4]. Various mechanisms may underlie $5 \mathrm{hmC}$ depletion in cancer such as mutations in TETs and IDHs $[1,22]$ and thus decreased expression of TETs and IDHs [3]. Published studies have shown that overexpressing TET2 in melanoma cells and TET1 in breast cancer cells increases their $5 \mathrm{hmC}$ content and decreases their malignancy in vitro and in vivo $[3,23]$. However, it might not be feasible to overexpress TETs in cancer patients as a therapeutic option. This study attempted to identify alternative means that may rebuild the $5 \mathrm{hmC}$ content in malignant cells as a potential treatment for cancer.
Contrary to what one might expect, more than $7 \%$ of the US population ( $>20$ million individuals) is estimated to be deficient in vitamin $\mathrm{C}$ (concentrations $<11.4 \mu \mathrm{M}$ in plasma) $[24,25]$. Further, the turnover rate of vitamin $C$ appears quite rapid, suggesting that the number of people with short-term vitamin $\mathrm{C}$ deficiency could be even higher [26]. Possibly due to the fact that it is nearly impossible to quantitatively control dietary vitamin $\mathrm{C}$ consumption in human subjects, an epidemiological link between vitamin $C$ deficiency and the incidence of melanoma has yet been published.

Interestingly, recurrent mutations in the splicing factor SF3B1 have been identified in certain types of melanoma [27]. The mutant SF3B1 causes a truncated, most likely nonfunctional, SVCT2 that can result in intracellular deficiency of vitamin C in cancer cells [28]. Besides a lower expression of TETs in melanoma cells as verified in this research, we also found that the expression of SVCTs was also significantly decreased especially in metastatic melanoma cell lines. This result suggests that a local deficiency of vitamin $\mathrm{C}$, due to less transporters in metastatic melanoma cells, could also be responsible for the loss of $5 \mathrm{hmC}$ in metastatic melanoma.

Based on the recent findings, including ours, [13-17] we sought to test whether vitamin $C$ could be an alternative of TETs overexpression to restore $5 \mathrm{hmC}$ in cultured melanoma cells. Distinct from previous studies of using pharmacological concentrations, we chose vitamin $\mathrm{C}$ at physiological concentrations, which can be conveniently reached by diet and dietary supplements, to treat cells. We showed that vitamin $\mathrm{C}$ treatment indeed reestablished $5 \mathrm{hmC}$ global content toward that in healthy melanocytes. Interestingly, higher concentration of vitamin $C$ did not cause an even higher level of $5 \mathrm{hmC}$ in melanoma cells, indicating that vitamin $\mathrm{C}$ at physiological levels can satisfy the need of TETs, though at low expression level, and maximize their enzymatic activity to generate $5 \mathrm{hmC}$ in melanoma cells. 
In addition to the changes in $5 \mathrm{hmC}$ content, vitamin $\mathrm{C}$ at physiological concentrations also caused phenotypic changes in cultured melanoma cells. In vitro assays showed that vitamin $C(0.1 \mathrm{mM})$ treatment decreased the malignant phenotype of A2058 cells by inhibiting cell migration and anchorage-independent growth, while exerting no obvious effect on proliferation rate. Published studies have shown that vitamin $\mathrm{C}$ depletion increases the growth and metastasis of melanoma cells in L-gulonolactone oxidase-knockout $\left(\mathrm{Gulo}^{-1-}\right)$ mice that mimic the human inability to synthesize ascorbate [29]. Further, supplementation of vitamin $\mathrm{C}$ could inhibit the growth and metastasis of melanoma cells in Gulo ${ }^{-/-}$mice [30]. These results suggest that vitamin $C$ treatment could decrease the malignant phenotype of melanoma in vitro and in vivo.

Consistent with the dual function of TETs and the consequent $5 \mathrm{hmC}$ on transcription regulation [31], vitamin C-induced $5 \mathrm{hmC}$ also correlated with bi-directional effects on transcription, although the most significantly altered transcripts were up-regulated. An ideal study will be an integrated analysis of RNA-seq and sequencing $5 \mathrm{hmC}$ in the genome of melanoma cells after vitamin C treatment. However, due to limits in financial support, a detailed $5 \mathrm{hmC}$ profiling by high-throughput sequencing can only be conducted in the future. Nevertheless, this research has successfully captured the most significant genes sensitive to vitamin C treatment in A2058 cells.

The most predominant change occurs in the ARHGAP30 gene, of which the expression is increased more than tenfold after vitamin $C$ treatment. Interestingly, not so much is known about the function of this gene. However, a recent report showed that ARHGAP30 is required for acetylation and functional activation in colorectal cancer. A low level of ARHGAP30 expression also is associated with poor survival of CRC patients [32]. A dramatic increase in ARHGAP30 expression caused by vitamin C can enhance the tumor suppressor activity of p53, further decreasing the malignancy. Thus, this study primarily links vitamin C to P53 in cancer treatment.

Furthermore, ECM remodeling appeared to be the primary pathway regulated by vitamin C. Other than GPRIN3, the most notable gene in this pathway is TIMP metallopeptidase inhibitor 3 (TIMP-3). Interestingly, overexpressing TET1 has been shown to activate TIMPs expression in breast cancer cells [23]. The mechanisms of how these altered genes contribute to the decreased malignancy of A2058 cells remain unclear and require further examination in the future.

Astonishingly, vitamin $\mathrm{C}$ is often absent in the formulation of the majority of media used for culturing cancer cells [33]. This suggests that the critical regulatory role of vitamin $C$ in the cancer epigenome might have been overlooked in previous cell-based studies. On the other hand, immunocompromised or genetically modified mice have been overwhelmingly used in cancer research. However, unlike humans, mice can synthesize vitamin $\mathrm{C}$ de novo. This implicates that previous mice-based studies might have ignored the effect of variation in vitamin $\mathrm{C}$ availability on the cancer epigenome.

In addition to restoring $5 \mathrm{hmC}$ in melanoma cells as described above, vitamin $\mathrm{C}$ at pharmacological doses also have been shown to inhibit the activity of DNA methyltransferases and to alter the expression of many miRNAs [34]. Besides these epigenetic pathways, the toxicity of vitamin $\mathrm{C}$ at $\mathrm{mM}$ ranges is also through reactive oxygen species pathways [35]. Taken together, vitamin $\mathrm{C}$, a safe and well-tolerated micronutrient, needs to be further evaluated in melanoma treatment.

\section{Conclusions}

Our study demonstrates that treatment of vitamin $\mathrm{C}$ at a physiological concentration can decrease the malignant phenotype of melanoma cells in vitro by partially reestablishing the global content of $5 \mathrm{hmC}$ and the consequent alteration in the transcriptome. These results suggest that vitamin $C$ could be a potential epigenetic treatment for melanoma and perhaps other types of cancer.

\section{Methods}

\section{Cell culture and treatments}

Melanocyte line (FOM-113), derived from a healthy human subject, and melanoma cell lines derived from radial growth phase (RGP, SBcl2 and WM35) and vertical growth phase (VGP, WM278 and WM3248) as well as metastatic phase (C8161) were gifts from Dr. M. Herlyn (The Wistar Institute). Another line of metastatic melanoma (A2058) was purchased from ATCC. Cells were cultured in the media as described [33]. The media used to maintain these cell lines did not contain any vitamin $\mathrm{C}$ in their formulas. After seeding in 6-well plates for $24 \mathrm{~h}$, cells were treated with vitamin C (L-ascorbic acid, Sigma-Aldrich, St Louis, MO, USA) at different concentrations for varying durations. Each treatment group consisted of three wells for every experiment. Each experiment was repeated at least three times.

\section{Quantitative real-time RT-PCR}

RNA was extracted from cultured melanocytes and various melanoma cells using RNeasy kits (Qiagen, Hilden Germany). A nanodrop 8000 photospectrometer was used to measure the yield of RNA extraction. The SuperScript III First-Strand Synthesis System (Invitrogen, Carlsbad, CA, USA) was used for reverse transcription (RT) according to the manufacturer's instructions. Quantitative realtime RT-PCR (qRT-PCR) was performed in triplicate on a Roche LightCycler 480. The 10- $\mu \mathrm{l}$ reaction contains SYBR Green master mix, primers, and diluted cDNA (100 ng). All primers were designed to span introns (Table 2). The 
Table 2 Primers for quantitative real-time RT-PCR

\begin{tabular}{|c|c|c|}
\hline Gene & Forwards $\left(5^{\prime} \rightarrow 3^{\prime}\right)$ & Reverse $\left(5^{\prime} \rightarrow 3^{\prime}\right)$ \\
\hline TET1 & AATGGAAGCACTGTGGTTG & ACATGGAGCTGCTCATCTTG \\
\hline TET2 & AATGGCAGCACATTGGTATG & AGCTTCCACACTCCCAAACT \\
\hline TET3 & GAGGAGCGGTATGGAGAGAA & AGTAGCTTCTCCTCCAGCGT \\
\hline SVCT1 & TCATCCTCCTCTCCCAGTACCT & AGAGCAGCCACACGGTCAT \\
\hline SVCT2 & TCTITGTGCTTGGATTTTCGAT & ACGTTCAACACTTGATCGATTC \\
\hline ARGHAP30 & GTGCCCCAGGTGCTAAAGAG & CTTGGAGGTAAACATCCCGAC \\
\hline TRIM63 & GCTITGAGAACATGGACTTCTIT & CTTCTGTGGACTCTTCCTCTTC \\
\hline PTPN7 & GGGAGGTCACCCTACACTITC & TGGTCTTGTATCGGTCCTTGG \\
\hline SOCS3 & GGAGACTTCGATTCGGGACC & GAAACTTGCTGTGGGTGACC \\
\hline FAP & CAAAGGCTGGAGCTAAGAATCC & ACTGCAAACATACTCGTTCATCA \\
\hline GPRIN3 & ATGGGGACTGTACCTGACCC & GGTGGTCTCATGCTCACAAAC \\
\hline TIMP3 & CGGTATCACCTGGGTTG & GTAGCCAGGGTAACCGAAA \\
\hline MAGEA4 & AGGAGCACCAAGGAGAAGAT & GCTTGCAGTGCTGACTCTT \\
\hline SERPINE4 & CTCGCCATGGTGATGAGATAC & CCTCACACTGGAACACATCTT \\
\hline SLITRK2 & CCTGGAAGCAGCGTCTTATT & CCTACTAAATCCTGCCCATCTC \\
\hline
\end{tabular}

transcript amplification results were analyzed with the LightCycler 480 software, and all values were normalized to the levels of the GAPDH using the $2^{-(\Delta \Delta \mathrm{Ct})}$ method. Statistical significance of differences in expression levels between melanocytes and different melanoma cell lines or between A2058 cells treated with or without vitamin C were assessed by Student $t$ test, at $\alpha=0.05$.

\section{Dot-blot assay}

Genomic DNA was extracted from cultured melanocytes and various melanoma cells using QIAamp DNA mini kits (Qiagen, Hilden Germany) according to the manufacturer's instructions. A Qubit Fluorometer (Life Technology, Foster City, CA, USA) was used to quantify the concentration of DNA. The dot-blot procedure followed the published methods as conducted in our previous studies [13]. Briefly, DNA samples were diluted with $2 \mathrm{~N}$ $\mathrm{NaOH}$ and $10 \mathrm{mM}$ Tris $\cdot \mathrm{Cl}$ and $\mathrm{pH} 8.5$ then loaded on a Hybond $\mathrm{N}+$ nylon membrane (GE Health, Piscataway, NJ, USA) using a 96-well dot-blot apparatus (Bio-Rad, Richmond, CA, USA). After baking at $80^{\circ} \mathrm{C}$ for $30 \mathrm{~min}$ and being blocked by $5 \%$ non-fat milk for $1 \mathrm{~h}$ at room temperature, the membrane was incubated in a polyclonal anti-5hmC antibody (Active Motif, Carlsbad, CA, USA; \#39769, 1:10,000) at $4^{\circ} \mathrm{C}$ overnight. $5 \mathrm{hmC}$ was visualized by chemiluminescence. The densities of the dots were captured by AlphaImager. To ensure equal loading, the membrane was stained with methylene blue postimmunoblotting. Statistical significance of differences in $5 \mathrm{hmC}$ content between different treatments were assessed by Student $t$ test at $\alpha=0.05$.

\section{MTT assay}

Cell growth was measured using MTT cell proliferation kits (BioVision Technologies, Exton, PA, USA) according to the manufacturer's instruction. Briefly, $5 \times 10^{3}$ cells/well were cultured in 96-well plates and cultured in the medium supplemented with or without vitamin $C$ as indicated in individual experiments. Samples were assayed in six replicates and these experiments were repeated three times.

\section{Cell migration assay}

Tumor cell migration was tested in transwell using BD Falcon FluoroBlok ${ }^{\mathrm{Tm}}$ Systems with an $8-\mu \mathrm{m}$ porous membrane insert (BD Biosciences, San Jose, CA, USA). A total of $1 \times 10^{4}$ A2058 melanoma cells were suspended in a $0.3-\mathrm{mL}$ serum-free medium and seeded in $8-\mu \mathrm{m}$ pore Fluoroblok inserts and left to migrate toward the lower chamber containing $0.7 \mathrm{~mL}$ of tumor medium with $1 \%$ FBS. Wells were divided into two groups (three wells/group) as follows: vitamin $C(+)$ and vitamin $C(-)$ groups. In the vitamin $C(+)$ group, vitamin $C(0.1 \mathrm{mM})$ was supplemented in both the insert and the low chamber. Cells were cultured at $37^{\circ} \mathrm{C}$ for $16 \mathrm{~h}$. Migrated cells were counted using an Olympus TH4-100 fluorescence microscope connected to a DP-70 Olympus digital camera (Olympus, Tokyo, Japan).

\section{Colony formation assay}

Tumor cell colony formation in soft agar was carried out as described [36]. Briefly, 3×10 A2058 melanoma cells per well were embedded into $0.33 \%$ agar gel containing FBS in 6-well plates pre-coated with $0.5 \%$ of agar solution 
in triplicate and covered with tumor medium supplemented with or without vitamin $C(0.01$ or $0.1 \mathrm{mM})$ or as indicated in the individual experiment. Medium was replaced every other day. Colonies (defined as a minimum of four cells) were counted after 15 days of incubation.

\section{RNA-seq}

A2058 cells cultured in 6-well plates were treated with or without vitamin $\mathrm{C}(0.1 \mathrm{mM})$ for $48 \mathrm{~h}$. Medium was changed daily before each treatment to avoid the accumulation of vitamin $\mathrm{C}$ in the medium. Total RNA was then extracted from these cells. A Bioanalyzer 2000 (Agilent, Palo Alto, CA, USA) was used to monitor the quality of RNA. All samples' RNA integrity numbers (RIN) were above nine (data not shown). The whole transcriptome sequencing was carried out at the Sequencing Core of John P. Hussman Institute of Human Genomics at the University of Miami. Briefly, after ribosome RNA (rRNA) was depleted, sequencing libraries were constructed following the standard Illumina protocols and were subsequently processed by a Hiseq2500 (Illumina, San Diego, CA, USA) sequencing system (200 bp paired-end reads, four samples per lane). Raw read data was first run through quality control metrics using FastQC (http: //www.bioinformatics.bab raham.ac.uk/projects/fastqc/). After quality control was checked, sequence reads were aligned using the STAR aligner [37]. The aligned reads from the STAR aligner was then run through HTseq for transcript quantification against the GENCODE v19.gtf file [38]. After all features were quantified, the data was then run through three different differential expression calculators in EdgeR, DESeq, and BaySeq [39-41]. The intersection of the three methods were taken and transformed into a list of the final differentially expressed features. Differentially expressed features were determined by cutoff adjusted $P$ values of 0.05 across all three methods. That final list was then put through gene ontology annotation using the BiNGO added into Cytoscape v 3.1.1 [42]. The list was also run through GeneGO for pathway enrichment (https://www.portal.genego.com).

\section{Statistical analysis}

All data were normalized by inner controls, such as GAPDH expression level. Data was presented as mean \pm SD. Statistically significant changes among treatments were assessed by Student $t$ tests at $\alpha=0.05$.

\footnotetext{
Abbreviations

5hmC: 5-hydroxymethylcytosine; 5mC: 5-methylcytosine; ARHGAP30: rho GTPase-activating protein 30; ECM: Extracellular matrix; GPRIN3: GPRIN family member 3; Gulo: L-gulonolactone oxidase; IDH: Isocitrate dehydrogenases; RGP: Radial growth phase; SVCT: Sodium-dependent vitamin C transporters; TET: Ten-eleven translocation family dioxygenases; TIMP3: TIMP metallopeptidase inhibitor 3; VGP: Vertical growth phase.
}

\section{Competing interests}

The authors declare that they have no competing interests.

\section{Authors' contributions}

The experiments were conceived and designed by GW, ZJL, and JWH. RNA-seq and quantitative RT-PCRs were performed by CBG. Dot-blot assay was conducted by KMD. HS and CY analyzed the melanoma cell malignancy. Bioinformatics and statistical analyses of the RNA-seq were done by DVB. The manuscript was written and reviewed by GW, CBG, ZLL, and JWH. All authors read and approved the final manuscript.

\section{Acknowledgments}

We thank Dr. M. Herlyn for providing melanoma cell lines. This research was supported by a James and Esther King biomedical research award (3KN08) to G.W. and an internal support of Department of Surgery to Z.J. L.

\section{Author details}

1John P. Hussman Institute for Human Genomics, Dr. John T. Macdonald Foundation Department of Human Genetics, University of Miami Miller School of Medicine, Miami, FL 33136, USA. ²Department of Surgery, University of Miami Miller School of Medicine, Miami, FL 33136, USA. ${ }^{3}$ Sylvester Comprehensive Cancer Center, University of Miami Miller School of Medicine, Miami, FL 33136, USA. ${ }^{4}$ Bascom Palmer Eye Institute, University of Miami Miller School of Medicine, Miami, FL 33136, USA. ${ }^{5}$ Department of Molecular Biology Laboratory, Shanghai Sixth People's Hospital, Shanghai Jiaotong University, Shanghai 200233, China.

Received: 5 December 2014 Accepted: 20 April 2015

Published online: 29 April 2015

\section{References}

1. Ko M, Huang Y, Jankowska AM, Pape UJ, Tahiliani M, Bandukwala HS, et al. Impaired hydroxylation of 5-methylcytosine in myeloid cancers with mutant TET2. Nature. 2010;468:839-43.

2. $\mathrm{Xu} \mathrm{W}$, Yang $H$, Liu Y, Yang $Y$, Wang $P$, Kim SH, et al. Oncometabolite 2-hydroxyglutarate is a competitive inhibitor of a-ketoglutarate-dependent dioxygenases. Cancer Cell. 2011;19:17-30.

3. Lian CG, Xu Y, Ceol C, Wu F, Larson A, Dresser K, et al. Loss of 5-hydroxymethylcytosine is an epigenetic hallmark of melanoma. Cell. 2012;150:1135-46

4. Gambichler T, Sand M, Skrygan M. Loss of 5-hydroxymethylcytosine and ten-eleven translocation 2 protein expression in malignant melanoma. Melanoma Res. 2013;23:218-20.

5. Tahiliani M, Koh KP, Shen Y, Pastor WA, Bandukwala H, Brudno Y, et al. Conversion of 5-methylcytosine to 5-hydroxymethylcytosine in mammalian DNA by MLL partner TET1. Science. 2009;324:930-5.

6. Ito S, D'Alessio AC, Taranova OV, Hong K, Sowers LC, Zhang Y. Role of Tet proteins in $5 \mathrm{mC}$ to $5 \mathrm{hmC}$ conversion, ES-cell self-renewal and inner cell mass specification. Nature. 2010:466:1129-33.

7. Kohli RM, Zhang Y. TET enzymes, TDG and the dynamics of DNA demethylation. Nature. 2013;502:472-9.

8. Ficz G, Branco MR, Seisenberger S, Santos F, Krueger F, Hore TA, et al. Dynamic regulation of 5-hydroxymethylcytosine in mouse ES cells and during differentiation. Nature. 2011;473:398-402.

9. Booth MJ, Branco MR, Ficz G, Oxley D, Krueger F, Reik W, et al. Quantitative sequencing of 5-methylcytosine and 5-hydroxymethylcytosine at single-base resolution. Science. 2012;336:934-7.

10. Yildirim O, Li R, Hung JH, Chen PB, Dong X, Ee LS, et al. Mbd3/NURD complex regulates expression of 5-hydroxymethylcytosine marked genes in embryonic stem cells. Cell. 2010;147:1498-510.

11. Mellén M, Ayata P, Dewell S, Kriaucionis S, Heintz N. MeCP2 binds to $5 \mathrm{hmC}$ enriched within active genes and accessible chromatin in the nervous system. Cell. 2012;151:1417-30

12. Spruijt CG, Gnerlich F, Smits AH, Pfaffeneder T, Jansen PW, Bauer C, et al. Dynamic readers for 5-(hydroxy)methylcytosine and its oxidized derivatives. Cell. 2013;152:1146-59.

13. Minor EM, Court BL, Young JL, Wang G. Ascorbate induces Ten-eleven translocation (TET) methylcytosine dioxygenase-mediated generation of 5-hydroxymethylcytosine. J Biol Chem. 2013;288:13669-74.

14. Dickson KM, Gustafson CB, Young Jl, Züchner S, Wang G. Ascorbate-induced generation of 5-hydroxymethylcytosine is unaffected by varying levels of iron and 2-oxoglutarate. Biochem Biophys Res Commun. 2013;439:522-7. 
15. Blaschke K, Ebata KT, Karimi MM, Zepeda-Martínez JA, Goyal P, Mahapatra S, et al. Vitamin C induces TET-dependent DNA demethylation and a blastocyst-like state in ES cells. Nature. 2013;500:222-6.

16. Yin R, Mao SQ, Zhao B, Chong Z, Yang Y, Zhao C, et al. Ascorbic acid enhances Tet-mediated 5-methylcytosine oxidation and promotes DNA demethylation in mammals. J Am Chem Soc. 2013;135:10396-403.

17. Chen J, Guo L, Zhang L, Wu H, Yang J, Liu H, et al. Vitamin C modulates TET1 function during somatic cell reprogramming. Nat Genet. 2013:45:1504-9.

18. Spielholz C, Golde DW, Houghton AN, Nualart F, Vera JC. Increased facilitated transport of dehydroascorbic acid without changes in sodium-dependent ascorbate transport in human melanoma cells. Cancer Res. 1997;57:2529-37.

19. Levine M, Padayatty SJ, Espey MG. Vitamin C: a concentration-function approach yields pharmacology and therapeutic discoveries. Adv Nutr. 2011;2:78-88.

20. Du J, Cullen JJ, Buettner GR. Ascorbic acid: chemistry, biology and the treatment of cancer. Biochim Biophys Acta. 2012;1826:443-57.

21. Suvà $M L$, Riggi $N$, Bernstein BE. Epigenetic reprogramming in cancer. Science. 2013;339:1567-70.

22. Figueroa ME, Abdel-Wahab O, Lu C, Ward PS, Patel J, Shih A, et al. Leukemic $\mathrm{IDH} 1$ and IDH2 mutations result in a hypermethylation phenotype, disrupt TET2 function, and impair hematopoietic differentiation. Cancer Cell. 2010;18:553-67.

23. Hsu CH, Peng KL, Kang ML, Chen YR, Yang YC, Tsai CH, et al. TET1 suppresses cancer invasion by activating the tissue inhibitors of metalloproteinases. Cell Rep. 2012;2:568-79.

24. Schleicher RL, Carroll MD, Ford ES, Lacher DA. Serum vitamin C and the prevalence of vitamin C deficiency in the United States: 2003-2004 National Health and Nutrition Examination Survey (NHANES). Am J Clin Nutr. 2009:90:1252-63.

25. Timpson NJ, Forouhi NG, Brion MJ, Harbord RM, Cook DG, Johnson P, et al. Genetic variation at the SLC23A1 locus is associated with circulating concentrations of L-ascorbic acid (vitamin C): evidence from 5 independent studies with >15,000 participants. Am J Clin Nutr. 2010;92:375-82.

26. Padayatty SJ, Levine M. New insights into the physiology and pharmacology of vitamin C. CMAJ. 2001;164:353-5.

27. Harbour JW, Roberson ED, Anbunathan H, Onken MD, Worley LA, Bowcock AM. Recurrent mutations at codon 625 of the splicing factor SF3B1 in uveal melanoma. Nat Genet. 2013;45:133-5.

28. Quesada V, Conde L, Villamor N, Ordóñez GR, Jares P, Bassaganyas L, et al. Exome sequencing identifies recurrent mutations of the splicing factor SF3B1gene in chronic lymphocytic leukemia. Nat Genet. 2011;44:47-52.

29. Cha J, Roomi MW, Ivanov V, Kalinovsky T, Niedzwiecki A, Rath M. Ascorbate depletion increases growth and metastasis of melanoma cells in vitamin C deficient mice. Exp Oncol. 2011;33:226-30.

30. Cha J, Roomi MW, Ivanov V, Kalinovsky T, Niedzwiecki A, Rath M. Ascorbate supplementation inhibits growth and metastasis of B16FO melanoma and 4 T1 breast cancer cells in vitamin C-deficient mice. Int J Oncol. 2013;42:55-64.

31. Wu H, D'Alessio AC, Ito S, Xia K, Wang Z, Cui K, et al. Dual functions of Tet1 in transcriptional regulation in mouse embryonic stem cells. Nature. 2011:473:389-93.

32. Wang J, Qian J, Hu Y, Kong X, Chen H, Shi Q, et al. ArhGAP30 promotes p53 acetylation and function in colorectal cancer. Nat Commun. 2014;5:4735.

33. Monfort A, Wutz A. Breathing-in epigenetic change with vitamin C. EMBO Rep. 2013;14:337-46

34. Venturelli S, Sinnberg TW, Berger A, Noor S, Levesque MP, Böcker A, et al. Epigenetic impacts of ascorbate on human metastatic melanoma cells. Front Oncol. 2014:4:227.

35. Sinnberg T, Noor S, Venturelli S, Berger A, Schuler P, Garbe C, et al. The ROS-induced cytotoxicity of ascorbate is attenuated by hypoxia and HIF-1alpha in the NCI60 cancer cell lines. J Cell Mol Med. 2014;18:530-41.

36. Balint K, Xiao M, Pinnix CC, Soma A, Veres I, Juhasz I, et al. Activation of Notch1 signaling is required for beta-catenin-mediated human primary melanoma progression. J Clin Invest. 2005;115:3166-76.

37. Dobin A, Davis CA, Schlesinger F, Drenkow J, Zaleski C, Jha S, et al. STAR: ultrafast universal RNA-seq aligner. Bioinformatics. 2013;29:15-21.

38. Anders S, Pyl PT, Huber W. HTSeq - A Python framework to work with high-throughput sequencing data. Bioinformatics. 2015;31:166-9.

39. Robinson MD, McCarthy DJ, Smyth GK. edgeR: a Bioconductor package for differential expression analysis of digital gene expression data. Bioinformatics. 2010;26:139-40.

40. Anders S, Huber W. Differential expression analysis for sequence count data. Genome Biol. 2010;11:R106.
41. Hardcastle TJ, Kelly KA. baySeq: empirical Bayesian methods for identifying differential expression in sequence count data. BMC Bioinformatics. 2010;11:422

42. Maere S, Heymans K, Kuiper M. BiNGO: a Cytoscape plugin to assess overrepresentation of gene ontology categories in biological networks. Bioinformatics. 2005;21:3448-9.

\section{Submit your next manuscript to BioMed Central and take full advantage of:}

- Convenient online submission

- Thorough peer review

- No space constraints or color figure charges

- Immediate publication on acceptance

- Inclusion in PubMed, CAS, Scopus and Google Scholar

- Research which is freely available for redistribution 